\title{
Community Based Conflict Mitigation Trials: Results of Field Tests of Chilli as an Elephant Deterrent
}

\author{
Malvern Karidozo*1 and Ferrel V. Osborn ${ }^{2}$ \\ ${ }^{1}$ School of Animal, Plant and Environmental Sciences, Wildlife Ecology, University of Witwatersrand, Johannesburg, South Africa \\ ${ }^{2}$ Connected Conservation Pty. Ltd. Hout Bay, Cape Town, South Africa
}

*Corresponding author: Karidozo M, University of Witwatersrand, Johannesburg, South Africa, Tel: +27117171000; E-mail: mkmalvern@gmail.com

Received date: December 13, 2014; Accepted date: January 13, 2014; Published date: January 20, 2014

Copyright: (C) 2015, Karidozo M, et al. This is an open-access editorial distributed under the terms of the Creative Commons Attribution License, which permits unrestricted use, distribution, and reproduction in any medium, provided the original author and source are credited.

\begin{abstract}
Mitigating human elephant conflict remains a major conservation and livelihood challenge across the elephant (Loxodonta africana) range states. Chilli-based methods for deterring elephants from raiding fields are being used by subsistence farmers in Southern Africa, but there is concern that these methods may not be effective, are too expensive and labour intensive to implement and that there is poor uptake by farmers. As part of an ongoing study examining these issues, we present our assessment of the effectiveness of chilli as a component of Community Based Conflict Mitigation in deterring elephants from raiding crops in Southern Zambia. Chilli-based deterrent methods namely the chilli fence and chilli briquettes were evaluated in protecting maize (Zea mays) crops. We monitored conflict incidences in the chilli fence protected plots and those in unprotected (control/reference) plots and those protected by a simple fence. We also monitored human-elephant conflict incidences in the plots protected by chilli briquettes against those in the control plots in order to assess the effectiveness of the mitigation measures. $A$ total of 46 Human Elephant Conflict incidences were recorded across the study site between January and April 2009 , with the highest incidences recorded in the month of February. We compared the number of plants destroyed by elephants and the number of attempted raids in both the test and control plots. In all the trials we noted that chillibased methods repelled elephants and provided protection for the crops as they experienced significantly less damage. We argue that chilli based deterrents assessed in these trials are effective in repelling elephants and do add deterrent value in mitigating human elephant conflict.
\end{abstract}

Keywords: Human elephant conflict; Community based conflict mitigation; Problem animal control; Chilli fence; Chilli briquettes

\section{Introduction}

The chronic issue of conflict between elephants and subsistence farmers threatens to undermine efforts to conserve wild populations who stray from protected areas. The conservation and management of wildlife in a landscape that has diverse anthropogenic activities has always been a challenge particularly in developing countries [1]. With $75 \%$ of elephant (Loxodonta africana) range across Africa outside protected areas, increasing human populations and concurrently increasing demands for land and resources, conflict between elephants and people has become commonplace and inevitable. This study is part of an ongoing attempt to find methods farmers can use to deter elephants from raiding their crops.

Human-Elephant Conflict (HEC) has existed for a long time: elephants may have limited agricultural development in equatorial forests for centuries [2] and recorded regularly throughout Africa from early twentieth century [3]. HEC is a problem that poses serious challenges for wildlife managers, local communities and elephants alike. In most cases, such negative interactions can undermine longterm biodiversity conservation goals because local people express their anger through encroachment on elephant habitat, poaching and excessive natural resource use [4]. Crop-raiding by elephants is the most prevalent form of human-elephant conflict and can result in devastating economic losses to farmers, loss of human lives, and the killing or capture of elephants in retaliation for these losses [5].
Mitigating human elephant conflict remains a major conservation and livelihood challenge across the elephant range states. A range of different and often-competing methods are being used including beehive fences [6], electric fencing [7] and chilli-based plus traditional methods [8] all with varying degrees of success. Human elephant conflict is a particularly pressing problem in Livingstone and Kazungula Districts of southern Zambia. According to the Zambian Wildlife Authority (ZAWA), 13 people and 22 elephants have died as a direct result of this conflict between the years 2006 and 2010 in this area [9]. If human-elephant coexistence is to be a realistic long-term goal, then conflict between people and elephants must be addressed. The development of methods to reduce crop depredations by African and Asian elephants is therefore a top priority for the conservation of these species $[1,2,5,10-12]$.

Chilli-based methods for deterring elephants from raiding fields are being used by subsistence farmers in Southern Africa, but there is concern that these methods may not be effective, are too expensive and labour intensive to implement and that there is poor uptake by farmers. Chilli peppers contains capsaicin, a chemical found in fruits of Capsicum spp., which is the agent that makes them taste hot by stimulating nociceptors of the trigeminal system [13]. The irritating quality of this stimulation produces a burning sensation that animals, in particular elephants, find unpleasant. Tests with oleo-resin and lowtech methods to deploy chilli showed considerable promise [14].

Criticism of chilli-based mitigation methods [12,15] developed by the Elephant Pepper Development Trust (EPDT) has prompted us to re-examine different aspects of these methods. EPDT encourages the use of low cost, simple and locally adaptable methods that make use of 
a combination of several strategies, a system that we have termed Community-Based Conflict Mitigation (CBCM) [14]. The critiques mainly focus on 1) the expense and labour of the application of chillibased methods, 2) the difficulty in application of these methods, 3) the uptake by farmers [15] and 4) the effectiveness of chilli pepper (Capsicum annum spp.) the active ingredient in the CBCM approach in repelling elephants [12]. It is also relevant to note that the authors have a considerable bias in that we are both involved in ongoing efforts to address HEC and to promote the use of the methods we developed. Due to the fact that ameliorating human-elephant conflict is fundamental to the future conservation of free ranging elephants and chilli-based methods are now being adopted in KAZA region (much without our involvement), we decided to publish the results of our trials.

To put the findings of this research in context, we decided to first address the question 'does chilli deter elephants?', and then address the practical questions posed regarding cost, labour and uptake of these methods in subsequent papers as recommended in Graham and Ochieng (2008). While the CBCM approach is based on farmers using a range of methods including increased vigilance, clearing buffer zones, using alarm systems and the use of chilli deterrents (such as string fences infused with chilli and burning chilli) we have found that assessing all the methods together in a systematic and scientific way very difficult. Therefore we decided to examine each aspect separately and publish the results in a series of manuscripts of which this is the first. We trialed and evaluated the effectiveness of two of the widely adopted and ironically most criticized chilli-based deterrents, with no farmers present. While we acknowledge that the study presented is of a limited spatial and temporal scale, we feel that the results are of sufficient relevance to practitioners developing their own mitigation strategies.

\section{Study Area}

The study was conducted in Livingstone and Kazungula districts of southern Zambia that share international boundaries with Botswana, Namibia and Zimbabwe. The rather flat topography (mean elevation $897 \mathrm{~m}$ ) measures $17,550 \mathrm{~km}^{2}$ and is covered with woodland and is broken only in a few points where marshes occur along seasonal streams [16]. The vegetation communities are mainly deciduous and comprise of woody species such as Colophospermum mopane, Burkea spp., Combretum spp., Parinari spp., Terminalia spp. And Acacia spp. as well as Adansonia digitata.

The area has a single rainy season, between the months of October and May with higher rainfall often recorded for the months of December and January with an annual average of $600 \mathrm{~mm}$ per annum [17]. Although the area is drought prone, subsistence crop farming is common and since the turn of the 21st Century, commercial irrigation based crop farming has been expanding [16]. The entire study area was originally prime wildlife habitat but with the development of Livingstone town, wildlife numbers have declined due to illegal killing of wildlife, dispersion into the neighbouring and protected areas in Zimbabwe as well as the reduction in suitable habitat as more land is converted to farmland, settlement and tourism enterprises [9]. Habitat in the community lands is largely intact but fragmented and disturbed in critical riverine areas by the land use practices of communities [16]. According to the last wildlife aerial census in the area in 2005, the study area has an estimated elephant population of 306 [18] which moves from the Mosi O Tunya National Park (MOTNP) which covers an area of $68.8 \mathrm{~km}^{2}$ into community lands as well as migrating between the neighbouring countries. The study was conducted in three chiefdoms (Sekute, Mukuni and Musokotwane) with a combined human population of 240,326 [19]. The Sekute Chiefdom is connected directly to Zimbabwe's protected areas in the south and to Botswana's Chobe National Park via the Impalia and Kasiki Conservancies in Caprivi (Namibia). A Zambezi river passage links northward with several forest reserves, but the area between the river and the main road has become congested with tourism lodges and commercial farms [16].

\section{Materials and Methods}

Two types of CBCM methods were tested for their effectiveness in repelling elephants from crop raiding, namely chilli fences and chilli briquettes.

\section{Chili fences}

Simple fences (defined by rough poles with string tied to them by hand) were made using $3 \mathrm{~m}$ poles placed at $5 \mathrm{~m}$ intervals along the perimeter of each trial plot. Two strands of sisal string were strung between the poles at $2 \mathrm{~m}$ and $1.5 \mathrm{~m}$ and two small square pieces of mutton cloth measuring $30 \mathrm{~cm} \mathrm{X} 15 \mathrm{~cm}$ were tied equidistant of each other in between consecutive poles. Chilli-oil was made from pounded dry chilli fruits (Capsicum spp. with an approximate Scovel unit of $25,000)$ mixed with used engine oil and applied on the sisal ropes, mutton cloth and poles. Two treatments and a control were examined; fields with chilli fence; fields protected by a simple string and mutton cloth fence and the control without any form offence or protection.

\section{Chilli briquettes (bricks)}

Chilli powder from pounded dry chilli fruits was mixed with rehydrated elephant dung at a ratio of 1:2 (one part chilli to two parts dung) and pressed into a brick mould. The bricks were dried in the sun and then ignited at the edges of the trial plots at sunset and left to smolder overnight producing an acrid chilli smoke that would linger around the plots depending on the wind velocity, direction and intensity. One treatment and a control were examined: those in which the chilli bricks were present and those without chilli bricks.

\section{Trial sites selection procedures}

Baseline HEC data was collected on four trial sites from October 2006 to March 2007 using an adapted version of the IUCN/AfESG elephant incident data collection form [20]. During the same period, four community meetings were held, one in each trial site. The objectives were threefold: a) to identify land for conducting trials; b) to solicit local knowledge of ranging patterns and crop raiding proclivities of elephants and c) to select village based field enumerators. Site selection was conducted after the community meetings and considered the following parameters; areas with a homogenous size, relatively uniform bio-physical attributes, relatively uniform elephant ranging patterns and HEC incidences recorded in the past as well as having no prior experience in using the trial methods. The sites selected were (a) Sons of Thunder Farm (SoTF), 25 $\mathrm{km}$ from Livingstone town and; (b) Natebe village, located $20 \mathrm{~km}$ from Livingstone town both under Musokotwane chiefdom; (c) Ngwenya village, located $5 \mathrm{~km}$ from Livingstone under Mukuni chiefdom and (d) Machenje village in Kazungula District, $75 \mathrm{~km}$ from Livingstone town under Sekute chiefdom (Figure 1). 


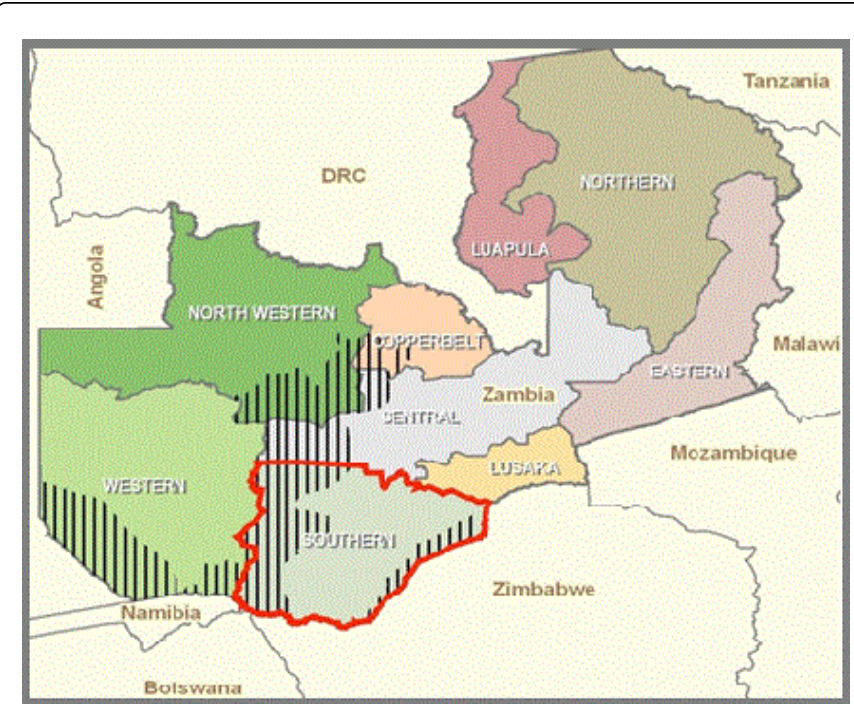

Figure 1: Map of study area: Top, Zambia's Provinces and below southern Province showing the position of Livingstone. (Sources: PCGIS, 2009)

\section{Trial sites layout}

For the chilli fence trials, a 1 hectare abandoned field was selected in each site and these fields were subdivided into nine equal square plots (Table 1) each measuring $20 \mathrm{~m} \mathrm{X} 20 \mathrm{~m}$ and a buffer zone measuring 20 m X 20 m equidistant from each treatment square plot was left fallow. At the beginning of the rain season of November 2008, maize (Zea mais) was planted in all the subdivided plots each having 300 plants. The timing was meant to coincide with the crop growing season of the communal farmers within the districts. The trial plots were approximately $2 \mathrm{~km}$ from the nearest local communities' fields (an arbitrarily selected distance) in an attempt to limit the effects of other deterrent measures used at the farmers' fields as well as being the average distance from the available abandoned fields. Three trial plots were fenced using the chilli fence; the other three had pieces of mutton cloth strung to a string fence without chilli smeared on them and the remaining three plots had neither fence nor chilli on them. All the treatment plots were arranged in a block design, selected randomly to allow for an equal probability of elephant raids. Maintenance of the chilli fence was done after every two days during the entire period of the study. Maintenance involved checking the need for re-application of chilli mixed with used oil at a ratio of 1:2 (chilli to used oil) as well as tightening the sisal string where it might have sagged. This was done by the enumerators. Chilli briquette trials were conducted on two one-hectare fields at least $800 \mathrm{~m}$ apart in each site over the same period. The fields selected measured $100 \mathrm{~m} \mathrm{X} 100 \mathrm{~m}$ and were not subdivided as in the chilli fence trial plots. In the test fields, each plot had a chilli briquette placed along the plot edges at $20 \mathrm{~m}$ intervals of each plot, every night at 20:00 hours or earlier if elephants had been sighted in the area. On average, the briquettes would smolder between 4-8 hours depending on the wind. The other one hectare field (the control) was left without any protection. During the rainy season, simple braziers were constructed to ward off rain and perforated on the sides for ventilation from where the chilli bricks would be burnt (Table 1).

\begin{tabular}{|c|c|c|c|c|c|}
\hline \multirow[t]{2}{*}{ Area } & \multicolumn{5}{|c|}{ Trial treatment relative to $\mathrm{HEC}$ incidences } \\
\hline & Chilli fenced & Simple fence & No fence & $\begin{array}{l}\text { Chilli } \\
\text { briquettes }\end{array}$ & $\begin{array}{l}\text { No chilli } \\
\text { briquettes }\end{array}$ \\
\hline $\begin{array}{l}\text { Sons of } \\
\text { Thunder }\end{array}$ & 3 & 3 & 3 & 3 & 3 \\
\hline Natebe & 3 & 3 & 3 & 3 & 3 \\
\hline Ngwenya & 3 & 3 & 3 & 3 & 3 \\
\hline Machenje & 3 & 3 & 3 & 3 & 3 \\
\hline
\end{tabular}

Table 1: Replicates and number of plots under each treatment

\section{Site monitoring and crop damage assessment}

The fields were monitored on a daily basis during the trial duration and after harvesting, the plots were abandoned. Paid enumerators and Zambian Wildlife Authority Problem Animal Control (PAC) teams provided details of elephant sightings and activity in the area. Elephant sightings were recorded in the form of herd size, distance from settlements and trial sites, herd composition (bull or cow groups) and other general comments regarding behaviour of the elephants. Crop damage reports including number of plants destroyed were collected in the control and trial plots and the totals were compared. Each crop damage incident was recorded and assessed to see whether it constituted an independent event, which was defined as a single foray occasion [21]. A raid was an incident in which elephants succeeded in destroying crops in a field by either consuming or trampling them. A visit constituted an unsuccessful raid in which elephants attempted to enter fields. The date and time of all incidents were noted and estimates were taken when the time of raid was unclear. Destruction of plants by any other means apart from elephant induced damage was also recorded as 'other damage'. Assessments for signs of elephant presence were made by searching for spoor in and around the fields [20].

\section{Assessing of the effectiveness of the defenses}

Evaluation of effectiveness of the deterrents was done by recording the number of incidences where elephants visited the plots and the proportion of elephant crop raiding attempts that were successful as well as those that were unsuccessful. An assessment of the number of 
plants destroyed in both trial and control plots were compared to assess the effectiveness of the methods.

\section{Results}

A total of 46 incidences (Figure 2) of human elephant conflict were recorded within the study area between November 2008 and April 2009. Five incidents were recorded in January, 19 in February, 12 in March and 10 in April. Although conflict is known to occur all year round in the study area, it peaked in the month of February. The number of elephant visits/attempted raids at each trial site was found to be similar ranging from 5 to 13 indicating that elephant pressure was relatively the same in each site during the trial period. In the chilli fence trials, 32 elephant visits were recorded and $50 \%$ of these were recorded as successful raids. Only $2(n=11)$ raids were successful on the 12 plots that were protected by the chilli fence, thus a raid success rate of $18.2 \%$ or $71.8 \%$ of the incidences resulted in elephants not destroying the chilli fenced trial plots. Two out of 12 chilli fenced fields were destroyed, that is $16.7 \%$ of the chilli fenced fields or $83.3 \%$ of the fields remained damage free. In contrast, of the 11 elephant visits on plots fenced with simple fences plus mutton cloth, $63.6 \%$ of these were rated successful raids $(n=7)$ and a combined $66.7 \%(n=7)$ of the 12 plots were destroyed. In the control plots; 7 (87.5\%) of the raids were successful $(n=8)$ with a combined total of 9 plots destroyed $(75 \%)$ from all the sites as shown in Table2.

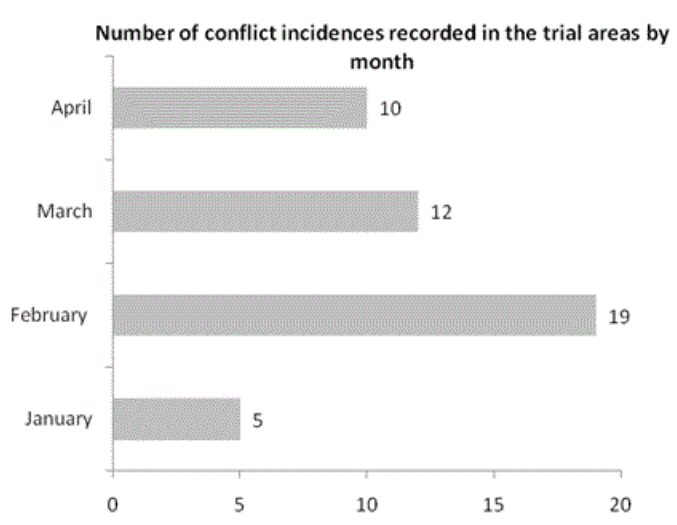

Figure 2: HEC incidences recorded over the study period in the entire trial site

\begin{tabular}{|l|l|l|l|l|l|}
\hline Site & $\begin{array}{l}\text { Numbe } \\
\text { r of } \\
\text { plots }\end{array}$ & $\begin{array}{l}\text { Number of } \\
\text { attempted } \\
\text { raids/ } \\
\text { elephant } \\
\text { visits }\end{array}$ & $\begin{array}{l}\text { Number of } \\
\text { plots } \\
\text { destroyed }\end{array}$ & $\begin{array}{l}\text { Total } \\
\text { Number } \\
\text { of plants } \\
\text { destroye } \\
\text { d }\end{array}$ & $\begin{array}{l}\text { Number } \\
\text { of } \\
\text { successf } \\
\text { ul } \\
\text { raids }\end{array}$ \\
\hline Chilli-fence & 12 & 11 & $2(16.7 \%)$ & 474 & $2(18.2 \%)$ \\
\hline $\begin{array}{l}\text { Mutton cloth } \\
\text { fence }\end{array}$ & 12 & 13 & $8(66.7 \%)$ & 1927 & $7(63.6 \%)$ \\
\hline Control & 12 & 8 & $9(75 \%)$ & 2596 & $7(87.5 \%)$ \\
\hline Total & 36 & 32 & $19(52.8)$ & 4997 & $\begin{array}{l}16 \\
(50.0 \%)\end{array}$ \\
\hline
\end{tabular}

Table 2: A comparison between the number of attempted and successful raids on different treatments
The number of plants and fields destroyed in all the treatments was also recorded and compared. Chilli fenced fields had the least number of fields and plants destroyed, all 474 plants in one site (Ngwenya) with all the other three sites not experiencing any damage. In contrast, a combined 1927 plants were destroyed across the test sites in mutton cloth fenced fields and 2596 plants were damaged in the control plots (Figure 3).

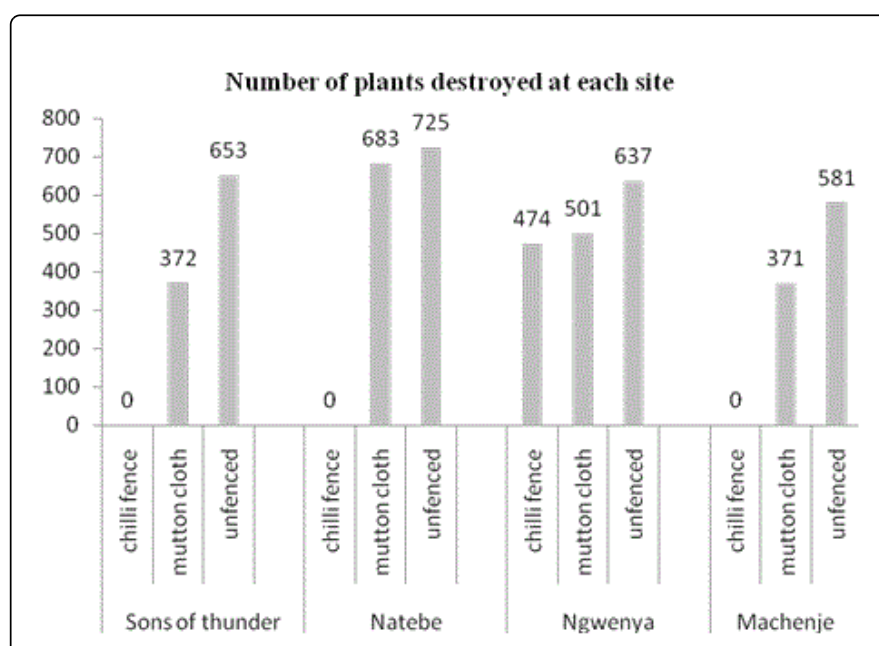

Figure 3: Number of plants destroyed in the chilli fence trials

In the chilli briquette tests, a combined total of 14 elephant incursion attempts into the trial and control plots were recorded. Five attempts were made against the plots protected by the smoldering chilli briquettes and 9 on the un-protected plots( Table 3). None of the attempts on the protected plots were successful hence no crops were destroyed in these plots. In contrast, $66.7 \%$ of the raids on unprotected fields were successful and as a result, $88.9 \%$ of the fields $(n=12)$ were destroyed, thus a combined 1729 plants from all the chilli briquette trial sites (Figure 4 ).

\section{Analysis}

The number of plants destroyed in the two tests and in both trial and control plots were tested for significance using the Pearson's Chi square test. The comparative analysis of raided and non-raided plots found that plots with chilli fences experienced statistically significant less damage compared to the control plots with relatively similar elephant visit incidents $\left(\chi^{2}, \mathrm{~F}=8.22, \mathrm{P}<0.05\right)$. There was also significant difference between the number of plants destroyed in chilli-fenced plots and those in mutton cloth fenced fields and the control plots $\left(\chi^{2}\right.$, $\mathrm{F}=1.15, \mathrm{P}<0.05)$.

We also compared the level of significance in the test and control plots in the chilli briquette experiment using the same Pearson's Chi Square test. There was significant difference in the number of fields destroyed between the chilli briquette trail plots and the control plots as none of the former fields were ever destroyed $\left(\chi^{2}, \mathrm{~F}=3.84, \mathrm{P}<0.05\right.$.). This indicated that chilli fenced fields and those protected by chilli briquettes suffered less damage than the control plots. 
Page 5 of 6

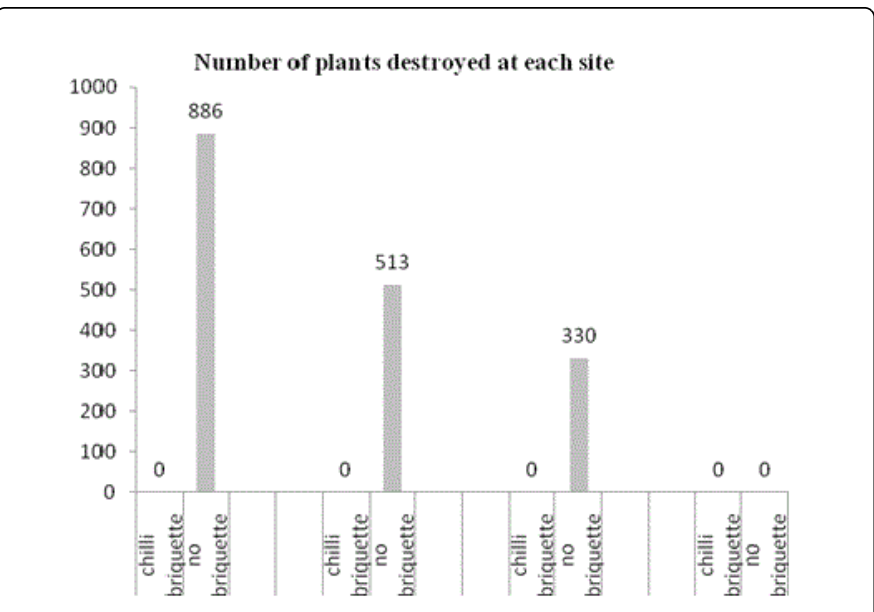

Figure 4: Number of plants destroyed in all the sites in the chilli briquette trial

\section{Discussion}

The data presented in this study indicate that chilli based CBCM methods possess repellency attributes towards crop raiding elephants. This is reflected in the high number of unsuccessful attempted raids on chilli protected fields and also the few plants destroyed in both the chilli fence and briquettes experiments. While measuring the effect of a potential deterrent on wild elephants is difficult, [22], chilli pepper, whose active ingredient, capsaicin, as a crop raiding elephant repellent, has been tested with success in the Gokwe Communal Lands of Zimbabwe, [23] where elephants had become habituated to traditional deterrents. Results of recent field trials of a capsaicin emitting gun, known as the "chilli dispenser" on elephants in Hwange National Park, Zimbabwe has also indicated that chilli does work in repelling elephants [24]. However, the mode of chilli dispersal in this study and the earlier trials are different. While no distinct relationship in the results was identified amongst the sites and between the two different techniques tested; a casual trend was apparent in that at all the four trial sites, no field on which the chilli briquettes were used had its plants destroyed. A possible explanation could be that chilli briquettes possess relatively more potent repellent properties than the chilli fence.

\begin{tabular}{|c|c|c|c|c|c|}
\hline Site & Number of plots & $\begin{array}{l}\text { Number of attempted } \\
\text { raids/elephant } \\
\text { visits }\end{array}$ & $\begin{array}{l}\text { Number of plots } \\
\text { destroyed }\end{array}$ & $\begin{array}{l}\text { Number of plants } \\
\text { destroyed }\end{array}$ & $\begin{array}{l}\text { Number } \\
\text { successful } \\
\text { raids }\end{array}$ \\
\hline Chilli-briquette & 12 & 5 & $0(0 \%)$ & 0 & $0(0 \%)$ \\
\hline Control & 12 & 9 & $8(88.9 \%)$ & 1729 & $6(66.7 \%)$ \\
\hline Total & 24 & 14 & 8 (33.3\%) & 1729 & $6(42.8 \%)$ \\
\hline
\end{tabular}

Table 3: Comparison of chilli briquette protected and unprotected fields

This is because the pungent smoke from smouldering chilli briquettes can travel relatively long distances such that elephants can smell it before they even reach the fields as elephants have a keen and acute sense of smell [13]. However, the chilli briquette method depends on the direction of the wind [24]. The brick has to be burnt in a situation where the smoke is blown in the direction of the elephants. Although the method is effective, it may not be applicable every day, which is its limitation [25].

Although not in the scope of this study, field notes and anecdotal data from various field sites we have been working with across part of the African elephant range states indicate more usage of the chilli briquette than the chilli fence. However, a possible explanation could be the cost (financial, labour, time, opportunity cost, etc) involved in the use of chilli fence as noted by Graham \& Ochieng (2007). A recent study in Ghana has shown the effectiveness of chilli fences in protecting farmers' fields [26].

A peculiar incident was observed in Ngwenya village in March 2009. In the trials, Ngwenya site is the only one that had plots protected by chilli fences destroyed. Two plots surrounded by a chilli fence were destroyed by two young bull elephants. The elephants pulled down the fence to get into the field using their hind legs with their trunks tucked in between the front legs. This is in contrast with common elephant behaviour when encountering a barrier. We are tempted to believe that the elephants were trying to avoid the chilli-oil smell and the messy mixture getting on their bodies and their trunks. This is further attested to by the elephant behaviour in the field whilst raiding the crops. The elephants appeared to be in haste and later, spoor evidence showed that more plants had been destroyed by trampling rather than consumption and observations and spoor noted that the elephants had left the field at a "brisk" pace, using the same entry point. It was noted that the elephants had moved several paces along the intact chilli fence and did not break it on their way out, instead; they turned to the broken fence where they had entered. While we are tempted to believe that chilli was behind this unusual elephant behaviour in crop raiding, it is important to note that other confounding variables could have triggered such behaviour. Elephants are known to be amongst the world's most intelligent species. They are able to radically change their behavior to face a new challenge, a hallmark of complex intelligence [27]. Elephants have also been known to drop very large rocks or tree branches onto an electric fence to either ruin the fence or cut off the electricity thus chilli irritation could have probably induced the noted behaviour in this case.

\section{Conclusion}

Results from the present study suggest that when executed properly i.e. regular maintenance of chilli fence and the frequent smoldering of numerous chilli briquettes do have the potential of repelling elephants from crop raiding. The observations in the study make it evident that protecting crops from elephant depredations with a chemical compound with which the elephants are less acquainted such as chilli could be effective. However, we recommend further tests in several places using the same and or an improvement of the methodology 
trialed in this study. Such replications over several farming seasons and in different situations will allow for conclusive evidence on whether chilli based CBCM methods can be deemed effective crop raiding elephant deterrents. We believe that there are no "blue-prints" in solving HEC and methods need to be varied and continuously evolving so that elephants do not easily habituate to the mitigation measures and CBCM attempts to address this. It is also important to make sure that methods be financially and technologically within capacities of people implementing them. It should also be noted that it is not easy to transpose a mitigation measure from one area to another and get the same results as most HEC situations are site specific and thus require different approaches. It has been noted that mitigating HEC and trialing different experiments may not be an exact science nor conservation per se but a management issue that require expertise from different sectors e.g. Agriculture Departments, Local Government, Land Boards and researchers. As such, we recommend a holistic and adaptive management in experimenting with mitigation measures.

\section{Acknowledgements}

We would like to thank the United States Fish and Wildlife Service (USFWS) and Wildlife Conservation Society (WCS) for funding the research. Many thanks to the communities involved in the trials for giving out land for the experiments and the Zambian Wildlife Authority for elephant sighting reports.

\section{References}

1. Hoare RE (2000) African elephants and humans in conflict: the outlook for co- existence. Oryx 34: 34-38.

2. Barnes RFW (1996) The conflict between humans and elephants in the central African forests. Mammal Review 26: 67-80.

3. Schweitzer A (1922) On the edge of the Primeval Forest. Adams \& Charles Black, London, UK.

4. Parker GE, Osborn FV, Hoare RE, Niskanen, LS (eds.) (2007) HumanElephant Conflict Mitigation: A Training Course for Community-Based Approaches in Africa.

5. Naughton-Treves L (1998) Predicting patterns of crop damage by wildlife around Kibale National Park, Uganda. Conservation Biology 12: 156-168.

6. King L, Lawrence A, Douglas-Hamilton I, Vollrath F (2009) Beehive fence deters crop-raiding elephants. African. Journal of Ecology 47: 131137.

7. Kioko J, Muruthi P, Omondi P, Chiyo P (2008) The performance of electric fences as elephant barriers in Amboseli, Kenya. South African Journal of Wildlife Research.

8. Sitati NW, Walpole MJ (2006) Assessing farm-based measures for mitigating human-elephant conflict in Transmara District, Kenya. Oryx 40: 279-286.

9. Zambia Wildlife Authority (2010) Problem Animal Control report book, Unpublished report, ZAWA, Livingstone, Zambia.
10. Hoare R (1995) Options for the control of elephants in conflict with people. Pachyderm 19: 54-63.

11. Kangwana KF (1995) Human-elephant conflict: the challenge ahead. Pachyderm 19: 11-14.

12. Hedges S, Gunaradi D (2010) Reducing elephant human conflict: Do chillies help deter elephants from entering crop fields? Oryx 44: 139-146.

13. Rasmussen LEL (1994) Sensory and Communication Systems. In: Mikota SK, Sargent EL, Ranglack GS (eds). Medical management of the Elephant. Indira Publishing House, West Bloomfield, Michigan, USA, 207-217.

14. Parker GE, Osborn FV (2006) Investigating the potential for chilli Capsicum annuum to reduce human-wildlife conflict in Zimbabwe. Oryx 40: 1-4.

15. Graham M, Ochieng $\mathrm{T}(2007)$ Uptake and performance of farm-based measures for reducing crop raiding by elephants Loxodonta Africana among smallholder farms in Laikipia District, Kenya. Oryx 4: 110-114.

16. Metcalfe S (2005) Landscape Conservation and Land Tenure in Zambia: Community Trusts in the Kazungula Heartland. African Wildlife Foundation Working Papers, 50 Independence Avenue Ridgeway, Lusaka, Zambia.

17. Metrological Office of Zambia (2009) State of the Environment: Zambia's southern Province, (Unpublished Report), Livingstone, Zambia.

18. Chase MJ (2006) The population status, ecology and movements of elephants in southwest Zambia. Report to: Conservation International, Kasane, Botswana.

19. Central Statistical Office (2009) (unpublished). Demography Status report for the Livingstone and Kazungula districts of Southern Province, Zambia, Livingstone, Zambia.

20. Hoare RE (1999) A Standardised Data Collection and Analysis Protocol for Human- Elephant Conflict Situations in Africa. IUCN African Elephant Specialist Group, Nairobi, Kenya.

21. Naughton L, Rose R, Treves A (1999) The social dimensions of humanelephant conflict in Africa: A literature review and case studies from Uganda and Cameroon. A report to the IUCN/SSC African Elephant Specialist Group's Human-Elephant Conflict Task Force. Unpublished Report, IUCN, Gland, Switzerland.

22. Karidozo M, Osborn FV (2005) Can Bees deter elephants from raiding crops? An experiment in the communal lands of Zimbabwe, Pachyderm 39: 26-32.

23. Le Bel S, Taylor R, Lagrange M, Ndoro O, Barra M, et al. (2007) A new reliable, low-cost, easy-to-use Capsicum delivery system for crop-raiding elephants in Zimbabwe: first results of a field test in Hwange National Park, CIRAD Zimbabwe.

24. Osborn FV (2002) Capsicum oleoresin as an elephant repellent: Field trials in the communal lands of Zimbabwe. Journal of Wildlife Management 66: 674-677.

25. Mupangwa JF, Nyabadza T, Mberengwa I, Chaipa I (2006) Problem Animal Control Strategies in Human Elephant Conflict areas of Dande Communal lands: A study in sustainability.

26. Wiafe ED, Sam MK (2014) Evaluation of a low-tech method, peppergrease, for combatting elephant crop-raiding activities in Kakum Conservation Area, Ghana. Pachyderm 55: 38-42.

27. Poole J (1996) Coming of Age with Elephants. Chicago Illinois Trafalgar Square 131: 143-144. 